\title{
DIGITAL TWIN AND 3D DOCUMENTATION OF A THEBAN TOMB AT DEIR AL-MEDINA (EGYPT) USING A MULTI-LENSES PHOTOGRAMMETRIC APPROACH
}

\author{
A. Mandelli ${ }^{*}$, C. Gobeil ${ }^{2}$, C. Greco ${ }^{2}$, C. Rossi ${ }^{1}$, \\ ${ }^{1}$ Architecture, Built environment and Construction engineering (A.B.C.) Department, Politecnico di Milano, Milano, Italy - \\ (alessandro.mandelli, corinna.rossi)@polimi.it \\ ${ }^{2}$ Museo Egizio, Torino, Italy - (cedric.gobeil, christian.greco)@museoegizio.it
}

Commission II, WG II/8

KEY WORDS: Heritage Documentation, Fisheye Photogrammetry, 3D Modelling, Archaeology, Theban Tombs.

\begin{abstract}
:
This paper describes the methodology employed in 2020 to perform the 3D survey of the Tomb TT214 at Deir al-Medina (Egypt). The aim of the archaeological mission was to integrate the evidence collected in the past on this tomb with a fresh survey a detailed study of some of its elements and an evaluation of its needs in terms of conservation. In order to achieve this result, the collapse that blocked the entrance to the burial chamber had to be removed, the courtyard was cleared, and the decorated walls and blocks were inspected and surveyed. Digital imaging was used to document all these phases and portions of the work. The aim of the survey team was to identify the most efficient combination of tools and methods to be used during these logistically complex operations, during which it was necessary to coordinate the work of various specialists and of the workmen, as well as to negotiate with the environmental difficulties and constrains. The survey was conducted at two scales, one for the architecture of the funerary complex and one for minute details such as inscriptions and decorations. Beside the routine process, both sets of data underwent a further level of elaboration, in order to extract and highlight further information. The final result of the survey was a navigable 3D model able to produce different outputs, all designed to support the archaeologists on the field and during the post-fieldwork phase of the elaboration of the results. The elaboration of such an integrated model may be paired to the progressive construction of a Digital Twin, a term born from the manufacturing and industrial realm but that may be successfully exported into the archaeological realm.
\end{abstract}

\section{INTRODUCTION}

Between January and February 2020, a team from Museo Egizio, Torino, in collaboration with the A.B.C. Department of Politecnico di Milano, started a new archaeological mission at Deir al-Medina, in Egypt, under the umbrella of the French mission of the Institut Français d'Archéologie Orientale (IFAO). The 2020 season focussed on the rock-cut tomb identified by the number TT214, which belonged to Khawy, his wife Taweret and his son Huy, who lived at Deir al-Medina during the reign of Ramesses II (New Kingdom, $19^{\text {th }}$ Dynasty, 1279-1213 BC).

The aim of this new mission was to integrate the scattered information on this tomb that had been collected in the past with fresh observations and elaborations, and to set them within a new framework. To this overall purpose, the 2020 fieldwork aimed in particular at two basic results: to remove the collapse that blocked the entrance and prevented the access to the burial chamber and to perform a 3D survey of the architecture and the decoration of the entire tomb. The specific aim of the latter was to provide a precise and accurate dataset from which, over the time, different information can be extracted to respond to various needs: first of all, those of archaeologists and specialists who will be working on the tomb and its contents, and then also for dissemination purposes (Rossi, 2019).

The survey activities also represented a chance to continue tests and investigations into the most efficient ways to use digital imaging to support an ongoing archaeological excavation, that is being started and developed from 2018 onwards by the Dutch-Italian mission at Saqqara of Museo Egizio, Torino and Rijksmuseum van Oudheden, Leiden, in collaboration with Politecnico di Milano (Del Vesco et al., 2019 and 2020).

\section{HISTORY OF THE SITE AND THE TT214 TOMB}

\subsection{Deir al-Medina}

Deir al-Medina is located in a desert hollow on the Nile West Bank of the Nile, opposite the ancient capital of Egypt in the New Kingdom, that now corresponds to the modern city of Luxor. The archaeological site includes the remains of a small and compact village, a religious area and a necropolis. The village was inhabited between 1500 to $1000 \mathrm{BC}$ by a community of workmen and craftsmen who quarried and decorated the royal tombs located in the nearby Valleys of the Kings and of the Queens (Figure 1) (Černý, 2001 (reed.); Valbelle, 1985).

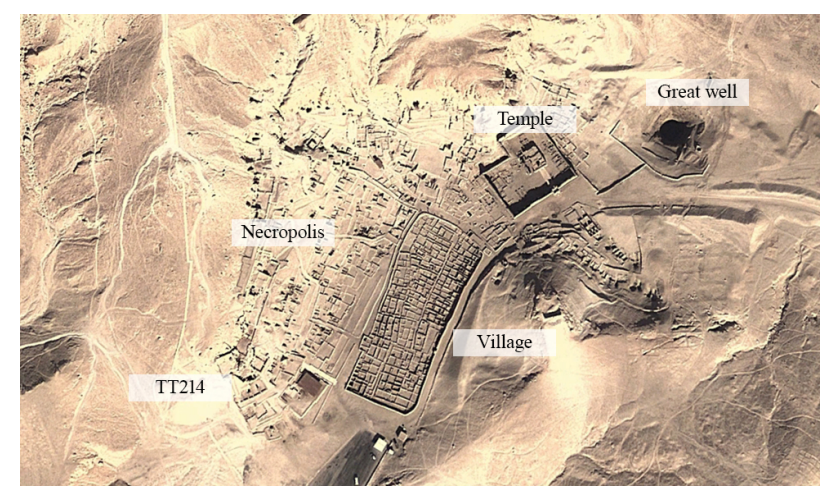

Figure 1. Deir al-Medina, Egypt, seen from the air. The position of TT214 is visible in the south-west area.

\footnotetext{
${ }^{*}$ Corresponding author
} 
The village was founded at the beginning of the $18^{\text {th }}$ dynasty during the reign of Thutmosis I (1504-1492 BC), then expanded westwards under Thutmosis III (1479-1425 BC), and southwards from Horemheb onwards (1323-1295 BC). In the Ramesside period the settlement reached the extent that is visible nowadays. During the reign of Ramses XI, the growing lack of order and security forced the inhabitants to leave the village and move into the fortified walls of the temple of Medinet Habu, located nearby at the edge of the cultivation. They only returned in the village on sporadic occasions, and the settlement was finally abandoned at the end of the New Kingdom, when the central power decided to stop burying members of the royal family in the Valleys of the Kings and of the Queens.

The village occupies the central hollow and is surrounded by the tombs of the inhabitants, that grew in number over the years. Houses and tombs yielded a wealth of objects and information on the daily life, social structure, religious beliefs and artistic skills of the community who lived and worked there.

\subsection{Excavations and site development of Deir al-Medina}

Deir al-Medina was visited, studied, and excavated by expeditions and independent individuals of different nationalities, including Bernardino Drovetti, Henry Salt, Karl Richard Lepsius, Auguste Mariette, Gaston Maspero and Georg Möller. A special mention concerns Ernesto Schiaparelli, who worked on the site during three seasons between 1905, 1906 and 1908 , and who discovered there the intact tomb of Kha and Merit, nowadays kept at Museo Egizio, Torino (Schiaparelli, 2007 (reed.)).

A systematic investigation of the area was carried out by Bernard Bruyère, starting from 1922. For almost 30 years, he cleared the village and its surroundings that were covered by centuries of sand: the western necropolis (1922-1933), the eastern necropolis (1934-1935), the village (1932-1935), the rest stop on the pass (1935), the temple and surroundings (19391940) and lastly the 'Great pit' (1949-1951). His extensive work was thoroughly recorded in his notebooks, that have been recently scanned and made available online on the website of the IFAO [https://www.ifao.egnet.net/bases/archives/bruyere/] Bruyère's published reports are also an endless source of knowledge for who wants to fully understand the site (Bruyère, 1924-1953).

Today Deir al-Medina is a UNESCO World Heritage site, and it is visited by thousands of tourists every year. The IFAO is engaged in operations of conservation, consolidation, and restoration to preserve the architectures (structures, tombs, houses, necropolis and temple) made of fragile mud bricks and dry stones.

The work here presented is only a small part of the ongoing topographical and architectural survey of the current state of the structures, which aims at identifying the most deteriorated and weakened sectors. These will then be the first areas to be consolidated and restored (IFAO, 2021).

\subsection{The tomb of Khawy (TT214)}

The subject of this study is the rock-cut tomb identified by the number TT214 (TT stands for Theban Tomb), which belonged to the guardian Khawy, his wife Taweret and his son Huy, who lived during the reign of Ramesses II. The tomb is nestled in the southern part of the necropolis on the west side of Deir alMedina. It was discovered between 1906 and 1913, and parts were later documented in more details by Bernard Bruyère (Bruyère, 1952).
From an architectural point of view, the tomb is composed of an open front courtyard, measuring about $6,60 \mathrm{~m}$ on each side (Figure 2), a chapel with a few carved decorations, and three underground burial chambers, the last one bearing a painted decoration on clay plaster. In 2014, an IFAO mission reopened the burial chamber to take pictures of the paintings, and then reburied the access for security and safety reasons.

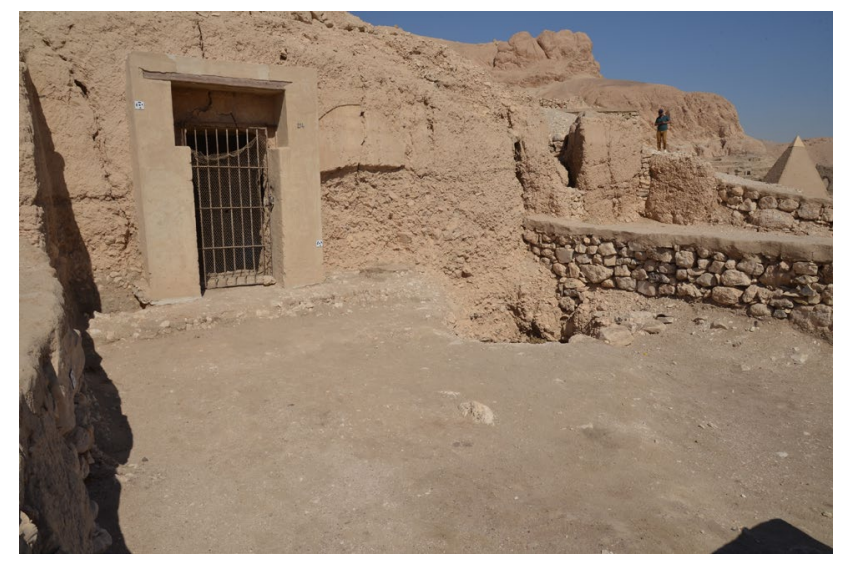

Figure 2. TT214, tomb of Khawy.

The chapel is at the same level than the one of the courtyard. The façade, the doorjambs, and the lintel are all decorated with carved inscriptions and drawings; fragments of decorated limestone blocks lie on the floor inside the chapel. A vertical shaft located in the north-eastern corner of the courtyard leads to the first and second subterranean chambers; the latter ends with a stair leading in turn, to the third and last burial chamber, the only decorated one.

The information previously collected on this tomb is scattered among a set of photos from the 1920's and a basic architectural sketch and notes made by Bernard Bruyère (Figure 3). In his 1927 report, Bruyère recounts that the rock above the ceiling of the second chamber collapsed that very year, sealing the access to the decorated burial chamber. Since then, this room has only been accessed once, specifically in 2014 by the IFAO mission for conducting a photographic survey (Gobeil, 2014).

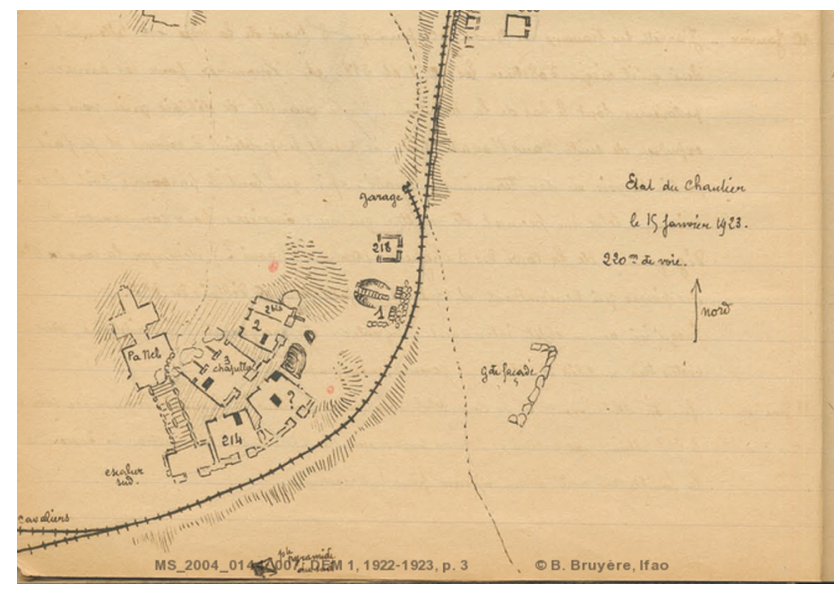

Figure 3. One of the sketches by Bruyère (Bruyère's Notebook, opposite to entry of 12 January 1923

[https://www.ifao.egnet.net/bases/archives/bruyere/?id=MS_20 04_0144_007]) 
The specific aims of the work performed in 2020 were to remove the collapsed material blocking the entrance to the burial chamber, consolidate the side walls, perform a 3D survey of the architecture and the decoration of the entire tomb, and to install a metal door with locks to ensure the protection and guarantee easy access for the future studies (IFAO, 2021).

These operations were performed by the archaeological team with the help of the Egyptian workmen; the survey was instead the task of the survey team of Politecnico di Milano and is the focus of this article.

\section{THE GEOMETRICAL SURVEY}

The expected result of the geometrical survey was a highresolution textured 3D model to be included in the framework of the other studies and surveys that are carried out by other archaeologists working in Deir al-Medina under the IFAO leadership.

The 2020 mission lasted 14 non-stop working days. The 3D survey was performed in several steps as it had to coordinate with several other activities that were being carried out at the same time in the small area of the tomb. At any rate, by the end of the mission the survey data were converted into a 3D model and the work was completed according to the plan and the schedule.

Three-dimensional models may be constructed by using laser scanners or photogrammetry. Scanners are expensive and fragile machines, and the sand-laden winds that batter the archaeological sites in Egypt do not encourage their use. Photogrammetry, on the other hand, is performed by means of simple cameras, which are easier to clean and -if necessary- to replace. Differently from laser scanners, the photogrammetric survey technique is able to generate extremely realistic threedimensional models, which record not only the shape but also the appearance and the colour of the object that is being recorded.

All these characteristics make photogrammetry a convenient and relatively easy method to be used on the field, especially in Egypt. Modern survey techniques nowadays allow the construction of models of any size, ranging from extremely small to rather large objects, and thus from tiny fragments to entire buildings. However, it is important to stress two characteristics of three-dimensional models that make a fundamental difference: their metricity, and the relationship between precision, accuracy and scale (Rossi, 2019).

\subsection{Topographic net}

The survey operations started together with the cleaning operations of the courtyard and the removal of the collapse. The first point of the net to relate to the existing reference system of the IFAO concession was placed in the court of the tomb next to the one of Khawy. The position of the first point is visible from three points belonging to the IFAO net, and therefore it was possible to determine its coordinates with the resection method; moreover, its lateral position prevented any interference with the movements of the workers. Two other strategic points were added: one on top of TT214, where the entrances of two shafts are visible, and one in the court once the cleaning operations were finished (Figure 4).

This allowed to create a local triangle net inside the global reference system. Almost 50 photogrammetric targets and 10 position of archaeological findings were measured from these three stations. The topographic net was measured using a Leica TCRA1103.

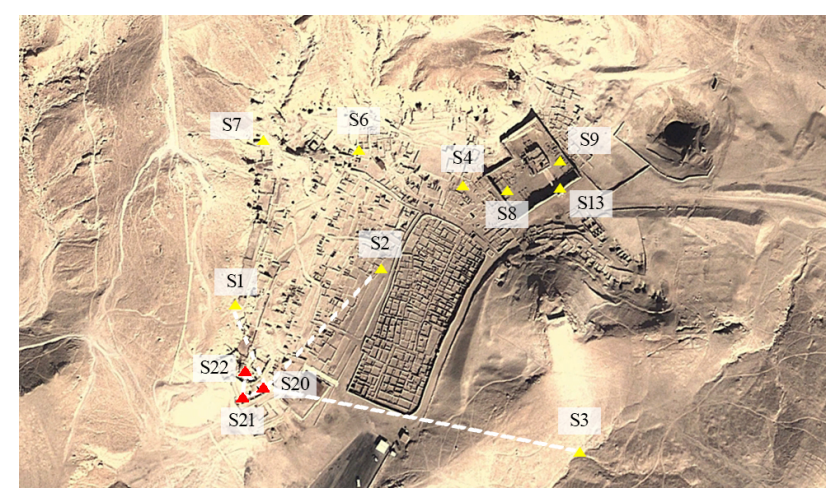

Figure 4. Topographic net.

\subsection{Multi-lenses photogrammetric survey}

As widely demonstrated (Fassi et al., 2015; Del Vesco et al., 2019, 2020; Mozas-Calvache et al., 2020) in logistic and environmental complex situations it is preferrable to adopt the photogrammetric technique rather than other performing survey instruments such as TLS (Terrestrial Laser Scanners) or mobile SLAMs (Simultaneous Localisation and Mapping). Their use is discouraged by an array of reasons, ranging from the difficulty to temporarily import them in Egypt, to their limited portability and their fragility when exposed to extreme environmental conditions.

Moreover, the photogrammetric approach allows for a high grade of versatility by always using the same camera body and changing the lenses, ranging from fisheye to telephoto lenses. Thus, the photographic equipment included a full-frame 50,6 Megapixel camera, namely the Canon EOS 5DS R Mark III, coupled with a Canon EF 8-15 mm lens, a Canon EF $20 \mathrm{~mm}$, and a Canon EF $35 \mathrm{~mm}$. Each one of these lenses demonstrated to be crucial for the survey activities. The lack of one of the lenses would have compromised the final result. The equipment also included two photographic flashes that proved to be extremely useful in the survey of the dark and steep underground chambers, located behind the tomb's chapel and dating to a previous period. The photogrammetric survey was organised to maintain a high standard in terms of acquisition of data but, at the same time, take up a short amount of time and avoid disruptions to the archaeological activities (Fassi et al., 2015; Mozas-Calvache et al., 2020).

The photogrammetric survey of the external parts of the tomb was spread along several days, of which only the short period between 5 and 6 am was used. TT214 is located on the eastern slope of the hollow of Deir al-Medina and in the morning gets very quickly filled by a strong sunlight projecting stark shadows, and thus the survey could only be performed before the sunrays reached the area. The $3 \mathrm{D}$ survey of the architecture was performed with the $20 \mathrm{~mm}$ and the fisheye lens, producing two different photogrammetric projects with significant overlapping parts. In these connecting areas the alignment of the project was possible thanks to the common photogrammetric targets, measured with the total station.

3.2.1 Canon EF $20 \mathrm{~mm} \mathrm{f} / \mathbf{2}, 8$ : During the planning of the mission, after studying the available data, the dimensions of the tomb and the aim of the work, this lens was chosen as main tool. In fact, considering the camera body and the focal length, in a range of $10 \mathrm{~m}$ distance from the object, the resolution was deemed to be more than enough for to obtain the customary 1:50 scale. To be precise, in this configuration, the formula to calculate the GSD in the case of rectilinear optical projection (Adami et al., 2018): 


\section{$C$ (focal length) $: D$ (capturing distance $)=$ pixel size $: G S D$}

returns a value of almost $50 \mathrm{~m}$ as maximum capturing distance when the GSD is equal to the plotting error at 1:50 scale (Mandelli et al., 2017). The $20 \mathrm{~mm}$ lens allowed the acquisition of all the data that had been planned in advance, namely those of the courtyard, the chapel, the three rooms, and the surroundings (such as the main staircase of the adjacent tomb of Paneb and the shafts on top of the tomb of Khawy. By the end of this survey, about 1.400 images were collected.

3.2.2 Canon EF 8-15 mm f/4L: As mentioned above, the back wall of the chapel had a hole leading in two directions: upwards to a shaft that leads on top of TT214, and downwards to a dark hole with a diameter measuring no more than $50 \mathrm{~cm}$.

Beyond the hole, the space opens into a bigger chamber the gives access to a series of other rooms placed at different levels, belonging to a set of earlier burials. Moreover, the first chamber has a way out in the upper part, through a second shaft that runs vertically in parallel to the other and that also comes out on top of TT214.

The tricky access and the unstable floor surface prevented the use of the total station, with or without the tripod, inside the underground chambers. Seemingly, using the $20 \mathrm{~mm}$ lens was not possible, due to the narrowness of the spaces.

The $3 \mathrm{D}$ survey of these chambers was possible thanks to the consolidated photogrammetric method based on the use of the fisheye lenses. The same approach and the elaboration workflow were already studied and tested by the survey team in different scenarios. Also, in this case the possibility to equip the camera with the fisheye lens played therefore a crucial role.

The use of a fisheye can significantly reduce the typical number of images required for indoor applications, simplifying the acquisition phase by limiting the size of the image dataset.

Previous experiments concerned the use of different lenses with their own photographic projections, from a circular Sigma $8 \mathrm{~mm}$ circular fisheye to a Samyang $12 \mathrm{~mm}$ diagonal fisheye and a Sigma 12-24 mm rectilinear lens (Perfetti et al., 2017; Barazzetti et al., 2017).

The peculiarity of the Canon EF 8-15 mm lens resides in the possibility to choose the proper projection in relation to the specific needs. In fact, it allows to pass from an $8 \mathrm{~mm}$ circular fisheye to a $15 \mathrm{~mm}$ rectilinear fisheye. The choice of using one projection rather than the other affects the area captured by each image, the number of photos, but also the overall resolution of the global 3D survey.

Considering the results obtained from the tests and the narrowness of the spaces, the decision was taken to use the at the maximum FOV (Field Of View) possible, holding the gear of the lens on $8 \mathrm{~mm}$ with an adhesive tape.

The fisheye survey covered: the chapel, the earlier burial rooms, and the shafts from the inside. All these areas were punctuated by coded photogrammetric targets to keep under control the reprojection errors during the subsequent alignment of the images. The images acquire for this photogrammetric project were 344 . The survey operations in the underground part of the tomb were difficult due to the total darkness, the breathing difficulty caused by the abundant dust that rose in clouds at any minimal movement, and by the presence of a colony of bats, unhappy to be forced to temporarily share their abode.

3.2.3 Canon EF $35 \mathrm{~mm} \mathrm{f/1,4:} \mathrm{When} \mathrm{the} \mathrm{outer} \mathrm{and} \mathrm{inner}$ surveys were completed and the correct alignment of the images verified, the survey team focussed on documenting in detail the reliefs incised inside and outside the chapel, as well as the loose blocks stored there. In this case, a $35 \mathrm{~mm}$ lens was used within a range between one meter and a few centimetres (Mandelli et al., 2019). The $35 \mathrm{~mm}$ photogrammetric survey included both the engraved stones still in situ and the 16 fallen fragments of reliefs; 7 of them belong to the right side of the chapel entrance, whilst others may not belong to this tomb. For each stone and fragment, a single photogrammetric project was performed, using coded targets and calibrated bars with a precision of 0,1 mm (Mandelli et al., 2019).

The aim of these surveys was manyfold. First of all, to document them and then to produce high resolution 3D models and orthophotos with the purpose of study and conservation. A by-product of this operation will be the possibility to digitally recompose the decorated jambs and the architrave and gain a clearer understanding of the inscriptions engraved on them. Finally, the detailed models of the reliefs of tomb TT214 are being used to expand the tests that were started on the reliefs of the tombs of Saqqara of the Dutch-Italian mission, based on the adoption of a combination of software able to highlight specific aspects of the incised surfaces (Figure 5), in order to increase the amount of information that may be derived from them and facilitate their study (Lori and Rossi, 2020).
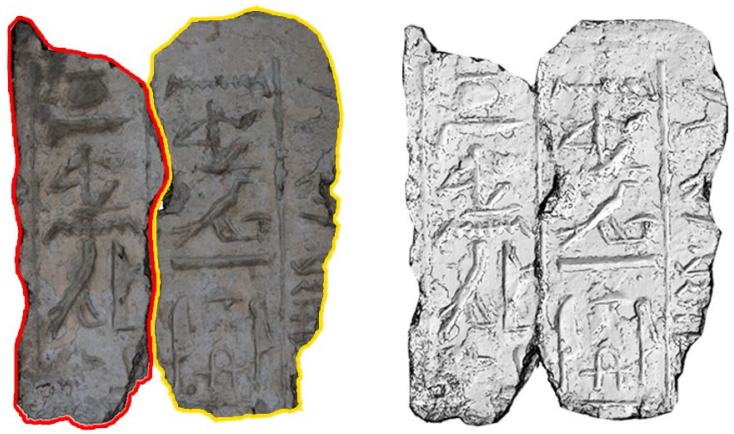

Figure 5. Enhanced readability of two reliefs, digitally recomposed. On the left the digital orthophoto, on the right the enhanced view using ridges filter and Lambertian $45^{\circ}$ lightning.

\section{DATA ELABORATION, DATA MERGING AND DELIVERABLES}

All the photogrammetric data were elaborated directly on site using Agisoft Metashape, by dividing the architecture in single projects according to the lens used for their specific surveys. Special attention was devoted to the fisheye photos: before any elaboration a mask was applied around the circular images in order to cover the black area around them, as well as to exclude the portions of the photos where the GSD degrades and prevents the possibility to reach the 1:50 drawing scale.

The radius of the masks was calculated following the method proposed in Perfetti et al. (2018). The method allows the operator to calculate the resolution distribution across the images beforehand, and, as a consequence, to monitor the minimum value of GSD for the various optical projections. As the lower resolution will influence the outcome of the photogrammetric process, it is important to understand which parts of the images can be used in relation to the chosen representation scale.

This method makes it possible to calculate the radius of the maximum circumference within which the resolution is compatible with the chosen scale; the remaining part, expressing a resolution lower than the acceptable minimum, can be discarded. 
The images were aligned at high resolution, thus downsizing the image by $1 / 4$ (Agisoft Metashape, 2021) and then each project was optimised and scaled using the measurements coming from the total station survey. The average error on measured targets was $0,004 \mathrm{~cm}$, that is compatible with the $1: 50$ drawing scale. The $20 \mathrm{~mm}$ and the fisheye projects overlap in two vast areas, the bottom of the chapel and the upper part the two shafts. Here the distance between the same measured targets is equal to $0,011 \mathrm{~cm}$, this value, too, falls within the desired accuracy.

Starting from these certainties, the 3D models were elaborated following two different methods: the 3D model of the $20 \mathrm{~mm}$ project was achieved using as source the dense cloud computed in high resolution. Since the dense cloud of the fisheye project was quite noisy, the 3D model of this dataset was instead built directly from the depth maps. The results were then exported in .obj format without texture, and then imported in Geomagic Design $\mathrm{X}$ to fix some topological problems, and to create a seamless, optimised 3D mesh, that has an anthill shape (Figure 6 ). At the end of the optimisation of the geometries, the model was re-imported in Agisoft Metashape and textured (Figure 7).

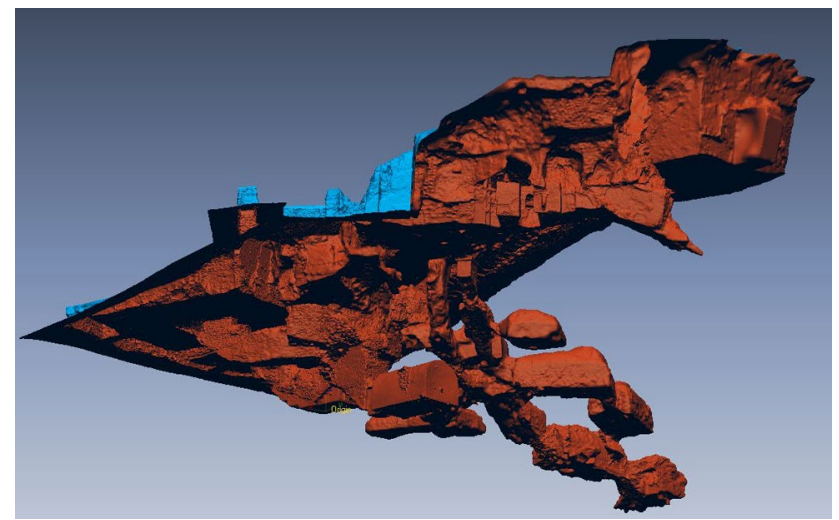

Figure 6. Seamless 3D mesh optimised in Geomagic Design X, bottom view.

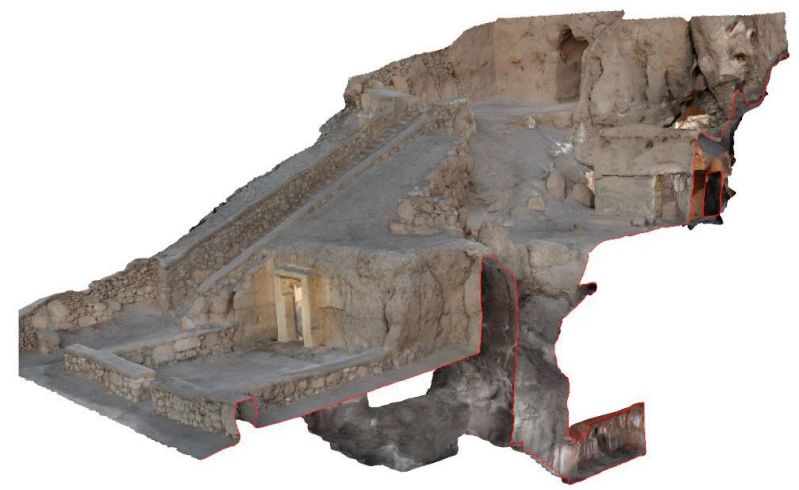

Figure 7. 3D model sectioned on the funerary chamber, top view.

The acquired and elaborated data gave the possibility to produce a multifaceted set of deliverables, to be used by the various specialist who were present on the site: detailed bidimensional drawings such as plans, sections, and elevations (Figure 8 and Figure 9), high resolution orthophotos of the scattered engraved fragments were among the output produced on the spot. A short $3 \mathrm{D}$ digital navigation of the tomb and further elaborations of the engravings were completed in the post-fieldwork processing phase.

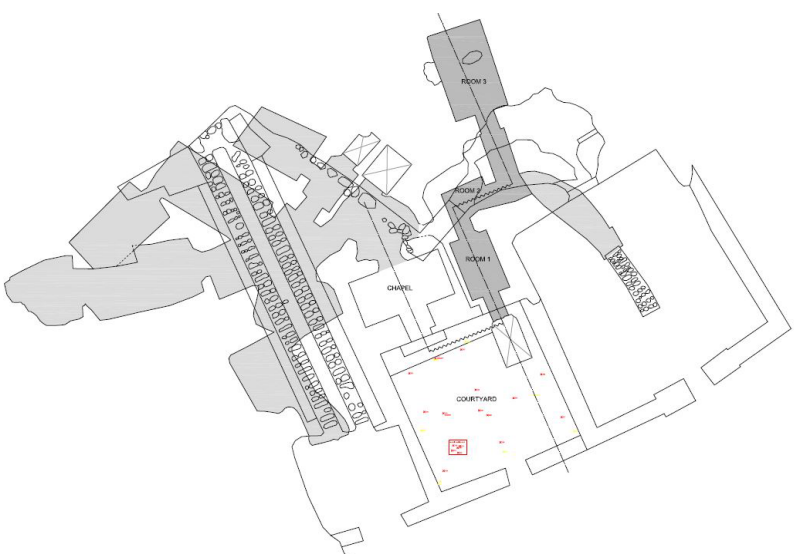

Figure 8. Plan of TT214.

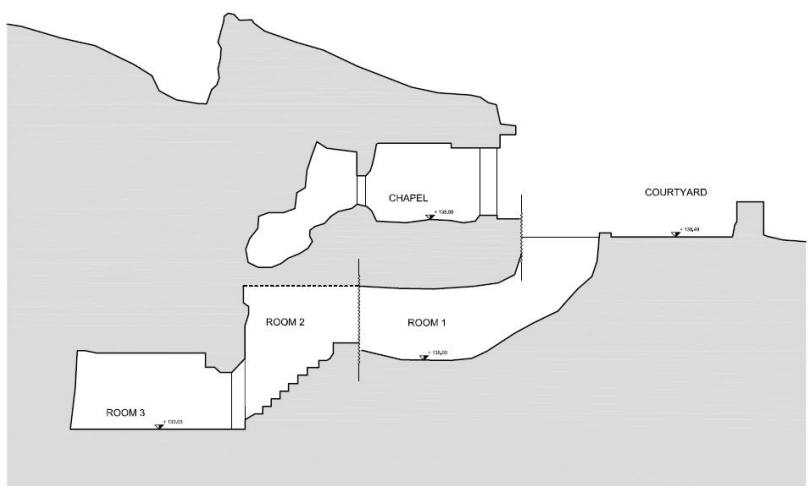

Figure 9. Section of TT214.

\section{BUILDING A DIGITAL TWIN}

3D data, images, historical information, and analyses on the findings may be collected in a single virtual environment, thus creating a Digital Twin (DT) of, in this case, the tomb of Khawy. Even if the term DT was originally developed to improve manufacturing and industrial process, the concept can be, in fact, extended to the field of $\mathrm{CH}$ (Cultural Heritage). In general, DTs represent digital replicas of physical entities that enable data to be seamlessly transmitted contents from physical to virtual worlds (Gabellone, 2020).

DTs consist of three fundamental components: i) the physical product in a real monitored space, ii) the data and information connections, iii) and the corresponding virtual product in the virtual space (Grieves et al., 2017). The data are communicated, stored, processed, and associated to the virtual product; this operation enables to enhance the awareness of the physical space and to operate simulations useful to decide how to later act in the real space, such as planning the construction of temporary supporting structures.

The potential application of DTs in the field of cultural heritage is their realistic representation in the form of an intelligent and semantically enriched 3D informative model (HBIM), a tool capable of managing collected and modelled information, and of improving availability and accessibility of the place (DezenKempter et al., 2020).

The most recent applications of this concept run both on a PC monitor and on the Oculus Rift headset (Oculus, 2020). It offers the possibility to interact by means of hand-held devices with 
the 3D model (of the architecture, as well as of single objects recorded at a higher resolution). The tool allows the interaction among objects and users even if they are all in different physical places. Each person connected with the virtual environment has an avatar that can speak, move, and share digital materials with other users. In this scenario, the 3D model can be enriched in a virtual environment with historical and didactic information and used for teaching, dissemination and valorisation purposes (Banfi, 2020).

Currently, this application appears to be more useful for dissemination purposes than for research. More work needs to be done to identify how to create a suitable virtual environment that would be really useful to help archaeologists and specialists to work remotely on the digital images. For instance, the high level of details reached by the metric survey (in this case of TT214) and the high quality of the images both of the external parts, and the paintings of the funerary chapel, may help architects and conservators to decide how to proceed with consolidation and restoration activities. The metric accuracy of the architectural survey, for instance, would allow to design the requested scaffoldings in advance without being physically on site.

TT214 represents an experiment that is being carried out to identify a workflow to be applied in the next future to other cases as well.

\section{FUTURE WORKS}

At the end of the 2020 mission, and in view of further fieldwork both there and at Saqqara, the survey team started to experiment how to improve the photogrammetric acquisition of deep vertical shafts, an issue that had already been faced at Saqqara in 2018 and 2019 (Del Vesco et al., 2020).

The problems were related to the swinging movement of the camera placed on a metal rod and lowered in the shaft. The infra-red remote shutter was affected by the large quantity of dust produced by the bar hitting the walls and the risk to damage the camera itself was significant. For these reasons, at the very end of the season, a wired wheeled cage was designed and assembled, ready to be used during the next season (Figure 10).

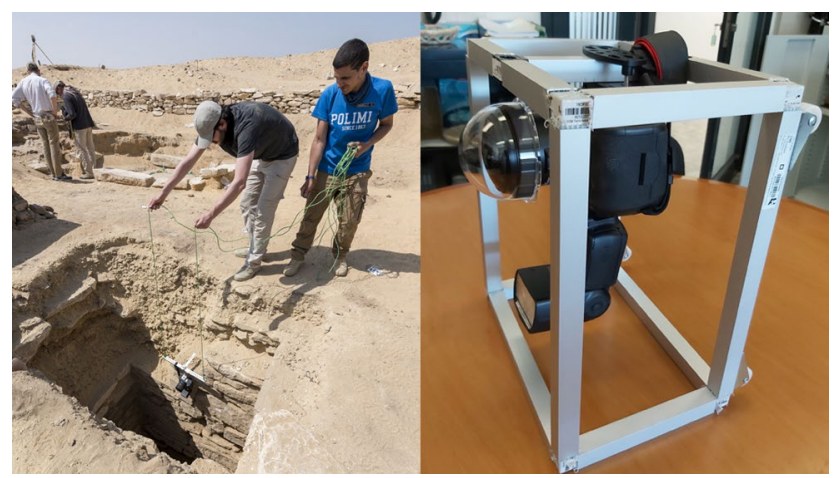

Figure 10. On the left the survey of a shaft in Saqqara in 2018, on the right the design of a wired wheeled cage to survey vertical shafts, designed and assembled in 2020.

The frame of the cage had a rectangular shape, and it is made by lightweight aluminium, it is easy to disassemble thanks to the plastic joints in the corners. On the back it presents four wheels that helps the cage going down in the shafts preserving the integrity of the camera. In addition, the Canon 8-15 mm lens is equipped with a Tadashi Fisheye Lens Protector, that should work as a further protection. The wireless remote shutter was replaced by a USB cable connected with a Windows rugged tablet that runs DigiCamControl software that lets the operator to check the framing of the camera, thanks to the video streaming on the screen, and to remotely control all the acquisition parameters

The camera is lowered by means of two ropes with marks each meter. These upgrades to the photogrammetric equipment should speed up the survey operations and improve the acquisition scheme made of regular strips parallel to the shaft walls with a constant base of acquisition.

\section{CONCLUSIONS}

The physical interaction with the site and the archaeological remains cannot be substituted. However, especially in this period in which travelling is extremely difficult, the results of reality-based photogrammetric surveys at various scales, carried out rapidly and efficiently, may offer a significant help to archaeologists: on the one hand, by reducing the time, the energy and the financial resources to be spent on site to collect the data, and then by offering a reliable dataset to efficiently work on the material from the distance, in the post-fieldwork phase of elaboration.

The identification of the most efficient combination of tools to be used on the field is therefore crucial: the choice must be made in strict collaboration with all the team members of the archaeological mission on the basis of the needs of the various specialists.

The real contribution of digital imaging to the archaeological investigation and the ensuing research is not necessarily the automatic application of the latest technologies, but rather the identification of the most productive means to answer the questions posed by the archaeologists.

\section{ACKNOWLEDGEMENTS}

The authors wish to thank the IFAO and Dr. Cédric Larcher, as well as their home institutions, Politecnico di Milano and Museo Egizio, Torino.

This article is the result of the research carried out by the project L.I.F.E., funded by the European Research Council (ERC) under the European Union's Horizon 2020 research and innovation programme (grant agreement No. 681673).

\section{REFERENCES}

Adami, A., Fassi, F., Fregonese, L., Piana, M., 2018: Imagebased techniques for the survey of mosaics in the St Mark's Basilica in Venice, Virtual Archaeology Review, 9.19, 1-20. ISSN 1989-9947, https://doi.org/10.4995/var.2018.9087.

Agisoft Metashape, 2021. www.agisoft.com

Banfi, F., Oreni, D., Bonini, J., 2020: The Arch of Peace of Milan and its historic memory: from 3D Survey and HBIM to Mixed Reality (VR-AR), Proceeding of $2^{\text {th }}$ International Conference of Representation Disciplines Teachers Congress of Unione Italiana per il Disegno. https://doi.org/10.3280/oa548.92 .

Barazzetti, L., Previtali, M., Roncoroni, F., 2017: Fisheye lenses for 3d modeling: evaluations and considerations. Int. Arch. Photogramm. Remote Sens. Spatial Inf. Sci., XLII-2/W3, 79-84. https://doi.org/10.5194/isprs-archives-XLII-2-W3-79-2017. 
Bruyère, B., 1924-1953: Rapport sur les fouilles de Deir el Médineh, Cairo.

Bruyère, B., 1952: Tombes Thébaines de Deir el-Médineh à décoration monochrome, Cairo.

Černý, J., 2001 (reed.): A Community of Workmen at Thebes in the Ramesside Period, Cairo.

Del Vesco, P., Greco, C., Soliman, D., Staring, N., Weiss, L., 2019: Current research of the Leiden-Turin archaeological mission in Saqqara. A preliminary report on the 2018 Season, Rivista del Museo Egizio, 3, 1-25. https://doi.org/10.29353/rime.2019.2236.

Del Vesco P., Greco C., Soliman D., Weiss L., 2020: The Leiden-Turin Archaeological Expedition to Saqqara: Preliminary Results of the 2019 Fieldwork Season, Rivista del Museo Egizio, $\quad$ 4, 1-32. https://doi.org/10.29353/rime.2020.3214.

Dezen-Kempter, E., Mezencio, D. L., De Matos Miranda, E., De Sà, D. P., Dias, U., 2020: Towards a digital twin for heritage interpretation, Proceedings of the $25^{\text {th }}$ CAADRIA Conference, 2, 183-191, Chulalongkorn University, Bangkok, Thailand, 5-6 August 2020.

Fassi, F., Rossi, C., Mandelli, A., 2015: Emergency survey of remote and endangered archaeological sites. Int. Arch. Photogramm. Remote Sens. Spatial Inf. Sci., XL-5/W4, 85-91. https://doi.org/10.5194/isprsarchives-XL-5-W4-85-2015, 2015.

Gabellone, F., 2020: A digital twin for distant visit of inaccessible contexts, Proceedings of IMEKO TC-4 International Conference on Metrology for Archaeology and Cultural Heritage, Trento, Italy, October 22-24, 2020.

Grieves, M., Vickers, J., 2017, Digital twin: Mitigating unpredictable, undesirable emergent behaviour in complex systems, in F.-J. Kahlen, S. Flumerfelt and A. Alves (eds.), Transdisciplinary perspectives on complex systems, Springer, Cham, 85-113.

Gobeil, C., 2014: Travaux de l'IFAO 2013-2014 - Deir elMedina 2014, Rapport d'activité 2013-2014 de l'Institut Français d'Archéologie Orientale du Caire, Supplément au Bulletin de l'Institut Français d'Archéologie Orientale 114, 7989.

IFAO, https://www.ifao.egnet.net/archeologie/deir-el-medina/
Lori F., Rossi C., 2020: 3D contour detection: a nonphotorealistic rendering method for the analysis of Egyptian $\begin{array}{llll}\text { reliefs. Antiquity, } & 94 & \text { (378), }\end{array}$ https://doi.org/10.15184/aqy.2020.211.

Mandelli, A., Achille, C., Tommasi, C., Fassi, F., 2017: Integration of $3 \mathrm{~d}$ models and diagnostic analyses through a conservation-oriented information system, Int. Arch. Photogramm. Remote Sens. Spatial Inf. Sci., XLII-2/W5, 497504, https://doi.org/10.5194/isprs-archives-XLII-2-W5-4972017, 2017.

Mandelli, A., Perfetti, L., Fiorillo, F., Fassi, F., Rossi, C., Greco, C., 2019: The digitalization of ancient Egyptian coffins: a discussion over different techniques for recording fine details. Int. Arch. Photogramm. Remote Sens. Spatial Inf. Sci., XLII2/W15, 743-750. https://doi.org/10.5194/isprs-archives-XLII-2W15-743-2019, 2019.

Mozas-Calvache, A. T., Pérez-García, J. L., Gómez-López, J. M., Martínez de Dios, J. L., Jiménez-Serrano, A., 2020: 3D models of the QH31, QH32 and QH33 tombs in Qubbet el Hawa (Aswan, Egypt). Int. Arch. Photogramm. Remote Sens. Spatial Inf. Sci., XLIII-B2-2020, 1427-1434. https://doi.org/10.5194/isprs-archives-XLIII-B2-2020-14272020, 2020.

Oculus, 2020. https://www.oculus.com/rift-s/

Perfetti, L., Polari, C., Fassi, F., 2017: Fisheye photogrammetry: tests and methodologies for the survey of narrow spaces. Int. Arch. Photogramm. Remote Sens. Spatial Inf. Sci., XLII-2/W3, 573-580. doi.org/10.5194/isprs-archives-XLII-2-W3-573-2017, 2017.

Perfetti, L., Polari, C., Fassi, F., Troisi, S., Baiocchi, V., Del Pizzo, S., Giannone, F., Barazzetti, L., Previtali, M., Roncoroni, F., 2018: Fisheye photogrammetry to survey narrow spaces in architecture and a hypogea environment. In Latest Developments in Reality-Based 3D Surveying and Modelling, Remondino, F., Georgopoulos, A., González-Aguilera, D., Agrafiotis, P., Eds., MDPI: Basel, Switzerland, 2018; 3-28.

Rossi, C., 2019: Immaterial data and material culture; surveying and modelling the new kingdom necropolis of Saqqara. Saqqara Newsletter, 17, 61-71.

Schiaparelli, E., 2007 (reed.): La tomba intatta dell'architetto Kha nella necropoli di Tebe (ristampa), Torino.

Valbelle, D., 1985: Les ouvriers de la tombe. Deir el-Médineh à l'époque ramesside, Cairo. 